\title{
Applying camera traps to detect and monitor introduced mammals on oceanic islands
}

\author{
LuCas LAMELAS - López and IVÁn SALGado
}

\begin{abstract}
The introduction of mammal predators has been a major cause of species extinctions on oceanic islands. Eradication is only possible or cost-effective at early stages of invasion, before introduced species become abundant and widespread. Although prevention, early detection and rapid response are the best management strategies, most oceanic islands lack systems for detecting, responding to and monitoring introduced species. Wildlife managers require reliable information on introduced species to guide, assess and adjust management actions. Thus, a large-scale and long-term monitoring programme is needed to evaluate the management of introduced species and the protection of native wildlife. Here, we evaluate camera trapping as a survey technique for detecting and monitoring introduced small and medium-sized terrestrial mammals on an oceanic island, Terceira (Azores). Producing an inventory of introduced mammals on this island required a sampling effort of 465 camera-trap days and cost EUR 2,133. We estimated abundance and population trends by using photographic capture rates as a population index. We also used presence/absence data from camera-trap surveys to calculate detection probability, estimated occupancy rate and the sampling effort needed to determine species absence. Although camera trapping requires large initial funding, this is offset by the relatively low effort for fieldwork. Our findings demonstrate that camera trapping is an efficient survey technique for detecting and monitoring introduced species on oceanic islands. We conclude by proposing guidelines for designing monitoring programmes for introduced species.
\end{abstract}

Keywords Azores, camera traps, introduced species, invasive mammals, oceanic islands, wildlife management

LuCAS LAMELAS-LÓPEZ ${ }^{*}$ (Corresponding author, (1) orcid.org/0000-0002-22307033) Departamento de Ciências e Engenharia do Ambiente, Universidade dos Açores, Rua Capitão João D’Ávila, São Pedro, Angra do Heroísmo, Açores, Portugal. E-mail lucas.l.lopez@uac.pt

IvÁN SALGADO (@ orcid.org/0000-0003-1652-5170) Departamento de Ecología Evolutiva, Museo Nacional de Ciencias Naturales, Consejo Superior de Investigaciones Científicas, Madrid, Spain

${ }^{*}$ Also at: Centre for Ecology, Evolution and Environmental Changes, Azorean Biodiversity Group, Angra do Heroísmo, Portugal

Received 28 March 2019. Revision requested 7 June 2019 .

Accepted 11 November 2019. First published online 19 October 2020.

\section{Introduction}

Tntroduced species threaten native biodiversity and nat1 ural resources (Vitousek et al., 1997; Doherty et al., 2016), are the second most important cause of biodiversity loss, after habitat destruction and fragmentation, and on islands have been the main driver of wildlife population declines and species extinctions (Millennium Ecosystem Assessment, 2005). Island ecosystems are particularly vulnerable to introduced mammals because of loss of antipredator behaviour in many island species (Blumstein \& Daniel, 2005), high rates of endemism (9.5 and 8.1 times higher than on the mainland for vascular plants and vertebrates, respectively; Kier et al., 2009), low species richness and simple trophic webs (Vitousek et al., 1995). High rates of species invasion and extinction of native fauna and flora on oceanic islands have resulted in biotic homogenization (i.e. the gradual replacement of native biota by introduced species; McKinney \& Lockwood, 1999).

The introduction of mammals is a major cause of species extinctions on oceanic islands (Biber, 2002), and most introduced mammal species became established after European colonization (Vitousek, 1988). Each new introduction of mammals increases the number of native species lost, and the probability of extinction is higher for oceanic island endemic species than for mainland species (Blackburn et al., 2004). The number of bird species that have become extinct following human colonization of oceanic islands is estimated to be in the hundreds to thousands (Blackburn et al., 2004), and most extinction events have occurred or are occurring in island ecosystems (Courchamp et al., 2003).

Eradication is only possible or cost-effective at early stages of invasion, before introduced species become abundant and widespread (Nogales et al., 2004; Howald et al., 2007). Although prevention, early detection and rapid response are the best management strategies, most oceanic islands lack systems for detecting, responding to and monitoring introduced species. Wildlife managers require reliable information on introduced species to guide, assess and adjust management actions, a process known as adaptive management. Thus, large-scale and long-term monitoring programmes are needed to evaluate the efficacy of eradication operations and confirm the removal of introduced species.

Efficient survey techniques are required to detect and monitor introduced species on islands. Camera trapping is an effective, non-invasive survey technique for monitoring wildlife (Silveira et al., 2003; Tobler et al., 2008), including 
introduced small (Rendall et al., 2014) and arboreal (Gregory et al., 2014) mammals. Camera traps provide data on multiple species at large spatial and temporal scales, with low impact on wildlife, and at low effort and cost (the relatively high initial cost is offset by the reuse of camera traps in subsequent studies; O'Connell et al., 2011). Camera trapping is effective for detecting rare, elusive or cryptic animals (Silveira et al., 2003; Tobler et al., 2008), as is the case for some introduced species. Camera-trap data can be used to define species distributions (González-Esteban et al., 2004) and estimate relative abundance and population trends (e.g. photographic capture rate; Rovero \& Marshall, 2009).

We evaluated camera trapping as a survey technique for detecting and monitoring introduced small and medium-sized terrestrial mammals on a remote oceanic island. We also report information on birds and reptiles, and we quantify the cost and sampling effort needed to complete the inventory of introduced mammals. Finally, we propose guidelines for designing programmes to monitor introduced species.

\section{Study area}

The Azores archipelago is a group of nine volcanic islands located in the North Atlantic Ocean, c. 1,500 km from Europe and 1,900 km from America. The Azores were uninhabited until Portuguese colonization in the 15th century, and since then many species have been introduced to the islands (Frutuoso, 1561). The archipelago is a high priority area for seabird conservation. Most native seabird species are categorized as Endangered at the regional scale (Cabral et al., 2005). Seabird populations have declined because of habitat loss, human exploitation and predation by introduced mammals, particularly rodents and feral cats (Monteiro et al., 1996). Some native species have become extinct or are confined to inaccessible cliffs and islets (Monteiro et al., 1996).

We conducted our study on the $402 \mathrm{~km}^{2}$ Terceira island, which rises up to 1,022 $\mathrm{m}$ altitude. Most human settlements are located in the coastal lowlands, where the native laurel forest has been transformed to pastures for cattle grazing. Native vegetation only remains in inaccessible highlands. All terrestrial mammals on Terceira have been introduced since the European colonization (Mathias et al., 1998): the feral cat Felis catus, ferret Mustela furo, weasel Mustela nivalis, rabbit Oryctolagus cuniculus, black rat Rattus rattus, Norway rat Rattus norvegicus, house mouse Mus musculus and hedgehog Erinaceus europaeus.

\section{Methods}

\section{Camera-trap survey}

We surveyed 72 locations on Terceira (Fig. 1) during October 2013-January 2015. We selected camera-trap

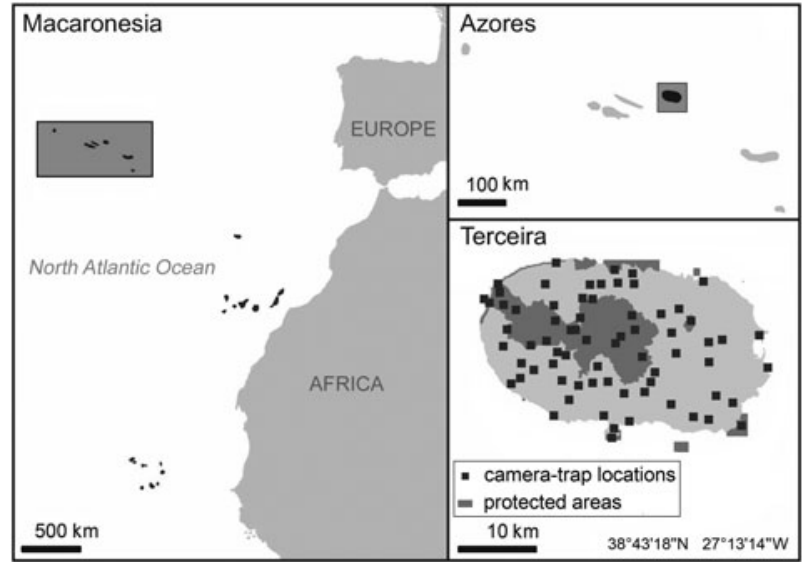

FIg. 1 Terceira is an island of the Azores archipelago, a group of nine volcanic islands in the North Atlantic Ocean, c. 1,500 km from Europe and c. 1,900 km from America, in the Macaronesia region.

locations at random, by creating random points in ArcGIS (Esri, Redlands, USA), but separated by at least $1 \mathrm{~km}$ to assure data independence (the home range size of the largest mammal on Terceira, the feral cat, is $<_{1} \mathrm{~km}^{2}$; Hervías et al., 2014). We set up one camera trap (Moultrie 88oi, Moultrie Feeders, Alabaster, USA, and Bushnell Trophy Cam, Bushnell Corporation, Overland Parks, USA) in each location, c. $30 \mathrm{~cm}$ above the ground and facing outward. Camera traps remained active for 8 days (Rendall et al., 2014) and recorded the date and time of each photograph. Camera traps were baited with meat or fish, fruit and molasses, and the sensitivity of the infrared sensor was set to high to increase photographic capture rates (O'Connell et al., 2011; du Preez et al., 2014).

\section{Data analysis}

We used EstimateS 9.1 to compute species accumulation curves (Colwell, 2013). Sampling units (i.e. locations) were randomized 1,000 times to remove entry order effects. We estimated the species richness at $95 \%$ CI with an incidence-based species richness estimator. Then, we used STATISTICA 10 (StatSoft, 2011) to fit the Clench asymptotic function, a non-linear regression model, to the smoothed species accumulation curve through the quasi-Newton method. The Clench model assumes that the probability of detecting new species increases with time (Soberón \& Llorente, 1993). We calculated the total number of introduced mammal species from the asymptote of the curve, because species richness (i.e. the cumulative number of species) is a function of sampling effort (i.e. the number of camera-trap locations). Finally, we estimated the minimum sampling effort required to complete the inventory of introduced mammal species.

We defined the photographic capture rate (number of photographs per camera-trap day) as an abundance index, 
and used PRESENCE 2.2 to build single-season occupancy models (Hines, 2006). We used presence/absence data from camera-trap surveys to calculate both the detection probability and estimated occupancy rate. We assumed constant detection probability $\mathrm{P}($.$) for occupancy modelling.$ We estimated the sampling effort (i.e. number of cameratrap days) needed to determine site-specific absence of each introduced mammal at 95\% CI (De Bondi et al., 2010).

We quantified expenditures in EUR to pay for cameratrap station equipment (camera traps, memory cards, batteries and bait) and for a working day (transport, rent and fuel for a $4 \times 4$ vehicle and salary of one field technician). Camera-trap equipment cost c. EUR 180 per station and we estimated the cost of a working day to be c. EUR 120. We added $10 \%$ to the overall cost to account for the replacement of damaged or stolen equipment. We expressed the survey cost as:

$$
\text { cost }=[120 \text { working days }+180 \text { camera traps }] \times 1.1
$$

As the number of working days depends on the number of locations and cameras, we transformed this equation into:

$$
\text { cost }=\left[120\left(\frac{\text { locations }}{\text { camera traps }}\right)+180 \text { camera traps }\right] \times 1.1
$$

Then we calculated the minimum value of this function for each sampling size to create a cost curve.

\section{Results}

Total sampling effort was 560 camera-trap days, and the mean sampling effort per site was $8.43 \pm$ SD 1.6 days. Samples from seven sites were excluded from the dataset because of camera-trap failures. We then included data from 65 locations in the analysis. Camera traps took a total of 10,558 photographs $(10,002$ of mammals, 500 of birds and 56 of reptiles). The mean capture rate was 18.85 photographs per camera-trap day. We excluded images of unidentifiable or non-target species (251 photos). Rats were the most common species $(8,588$ photos) and were present at $86.2 \%$ (R. rattus) and $30.8 \%$ ( $R$. norvegicus) of sites, whereas mice were less common (77 photos; $15.7 \%$ of sites). Cats were the most common carnivore ( 902 photos; $24.6 \%$ of sites). Rabbits were common (310 photos; $32.3 \%$ of sites), and hedgehogs were recorded 40 times, at $10.8 \%$ of sites. Mustelids were least frequently captured (14 photos) and were present at $9.2 \%$ (weasel Mustela nivalis) and 3.1\% (ferret Mustela furo) of sites. A total of eight mammal species (Plate 1), 17 bird species and one reptile species were recorded (Table 1). The species accumulation curve approached an asymptote after recording eight mammal species (Fig. 2). Rats were the most widespread species, with an estimated occupancy rate of $85 \%$. The estimated occupancy rate of mustelids was $<10 \%$. The detection probability exceeded $90 \%$ for most species, except the hedgehog (29\%) and mustelids ( 7 and $5 \%$ for weasel and ferret, respectively). The sampling effort required to determine absence was adequate for all species, except for mustelids (Table 2).

The sampling effort required to capture the most common introduced species (rodents, cats and rabbits; five species, $62.5 \%$ of all introduced mammal species) was 34 camera-trap days, at a cost of c. EUR 60o. The sampling effort required to capture also the less common species (the weasel and hedgehog; to a total of seven species, $87.5 \%$ of the introduced mammals) was 129 camera-trap days (EUR 1,073 ), and to capture all eight introduced species, including the rarest (the ferret), was 465 camera-trap days (EUR 2,133; Fig. 2).

\section{Discussion}

Camera trapping has become common in wildlife research. It is more efficient than other survey techniques such as live trapping, line transects, track plots or hair snares (Lyra-Jorge et al., 2008; De Bondi et al., 2010; Monterroso et al., 2014; Wearn \& Glover-Kapfer, 2019). Our findings confirm that camera trapping is a cost-effective survey technique for detecting and monitoring introduced mammals on oceanic islands. We have recorded all wild mammals known to have been introduced to Terceira island (eight species; Borges et al., 2010), with a relatively low sampling effort (465 camera-trap days) and at low cost (EUR 2,133).

We used camera-trap data to estimate abundance, detection probability, site occupancy rate and the sampling effort required to determine site-specific absence of introduced species. We detected rats and rabbits with a low sampling effort ( $<50$ camera-trap days). Rats and rabbits are common (detection probability $>90 \%$; photographic capture rate $>50$ photographs/100 camera-trap days) and widespread (estimated occupancy $>30 \%$ ) species on Terceira, as has been reported earlier (Mathias et al., 1998). However, we needed c. 500 camera-trap days to detect the rarest species, the ferret. Mustelids are rare (detection probability $<10 \%$; photographic capture rate $<5$ photographs/100 camera-trap days) and occur in few locations (estimated occupancy $<10 \%$ ) on Terceira. Mathias et al. (1998) reported that the ferret is rare in the Azores archipelago, except on Flores island. Camera trapping is thus useful to detect and monitor elusive and rare species.

\section{Recommendations for camera-trap surveys}

We propose the following questions to guide the survey design to monitor introduced mammals on oceanic islands: How many camera-trap locations should be sampled (sample size)? How many camera-trap days are needed to sample 

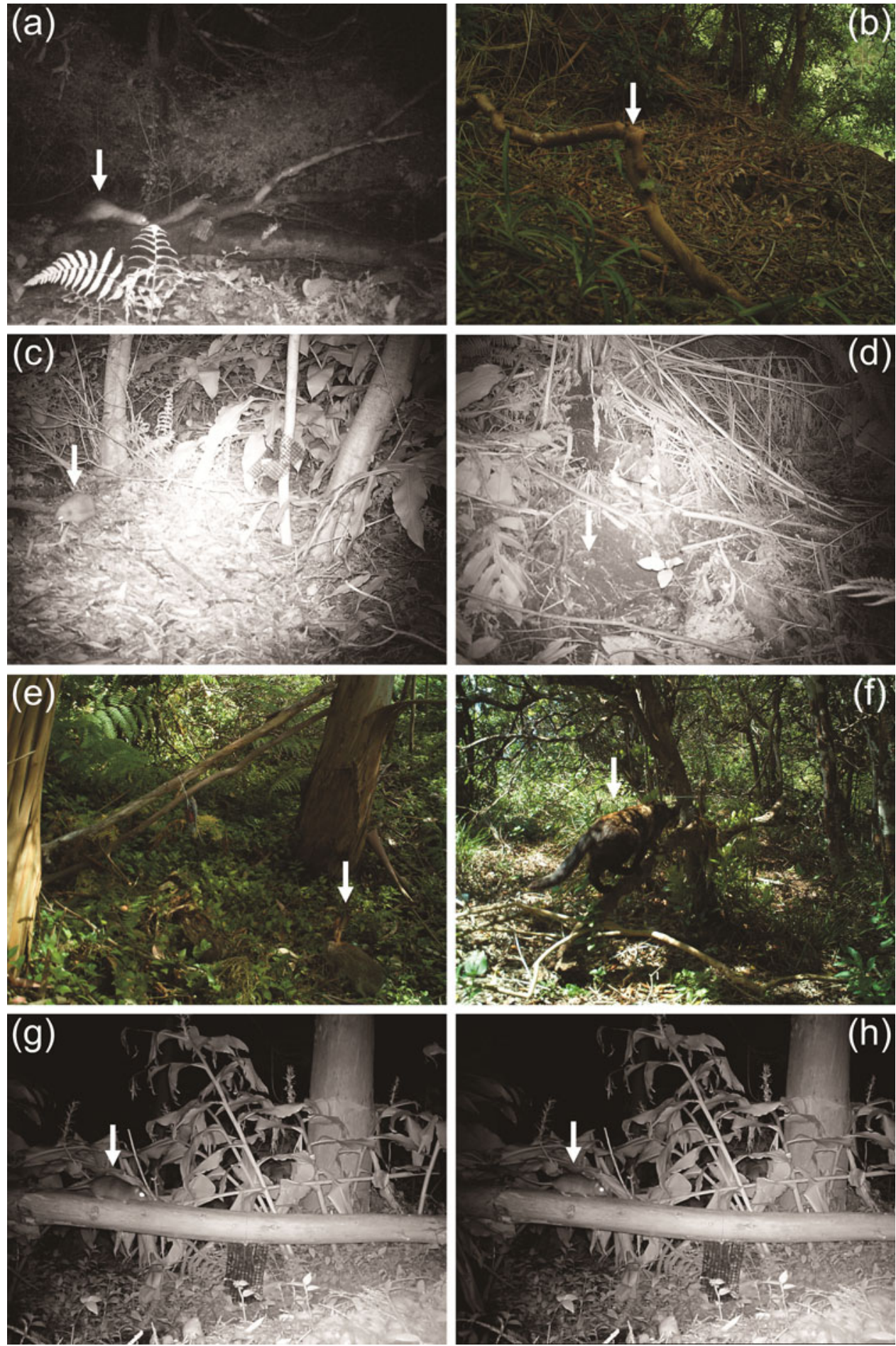

Plate 1 Photographic captures of introduced mammals:

(a) ferret Mustela furo, (b) weasel Mustela nivalis, (c) hedgehog Erinaceus europaeus, (d) house mouse Mus musculus,

(e) European rabbit Oryctolagus cuniculus, (f) domestic cat Felis catus, (g) Norway rat Rattus norvegicus, (h) black rat Rattus rattus.

each location (sampling effort)? When is the best time to carry out the survey (sampling period)? How should camera traps be spaced (camera-trap density)? Where should camera traps be facing (camera-trap setup)? How much will the survey cost (economic cost)?

The number of camera-trap locations depends on the island's size and habitat diversity (Hortal et al., 2009; Whittaker et al., 2017). We recommend separating the sampling locations by at least $1 \mathrm{~km}$, as in previous studies (Silveira et al., 2003; Tobler et al., 2008; Pettorelli et al., 2010; Olson et al., 2012; Hedwig et al., 2018). We detected all eight introduced mammal species on Terceira $\left(402 \mathrm{~km}^{2}\right)$ by sampling 65 locations (i.e. 1 camera trap $/ 6.2 \mathrm{~km}^{2}$ ). According to Tobler et al. (2008), camera density and sampling area have a relatively minor effect on the number of species detected, compared to sampling effort. 
TABLE 1 Wildlife inventory through camera trapping in Terceira island (Azores archipelago). Number and percentage of presence sites, and photographic capture rates (photographs/10o camera-trap days) as a relative abundance index.

\begin{tabular}{|c|c|c|c|c|c|}
\hline Order (by class) & Family & Species & Presence sites & Photographs/100 trap days & Range $^{1}$ \\
\hline \multicolumn{6}{|l|}{ Mammalia } \\
\hline \multicolumn{6}{|l|}{ Carnivora } \\
\hline & Mustelidae & Mustela furo & $2(3.1 \%)$ & $0.71(0.04 \%)$ & Introduced \\
\hline & & Mustela nivalis & $6(9.2 \%)$ & $2.50(0.13 \%)$ & Introduced \\
\hline & Felidae & Felis silvestris catus & $16(24.6 \%)$ & $164.59(8.62 \%)$ & Introduced \\
\hline \multicolumn{6}{|l|}{ Rodentia } \\
\hline & Muridae & Mus musculus & $10(15.7 \%)$ & $14.05(0.74 \%)$ & Introduced \\
\hline & & Rattus norvegicus & $20(30.8 \%)$ & $1,567.15(82.14 \%)$ & Introduced \\
\hline & & Rattus rattus & $56(86.2 \%)$ & & Introduced \\
\hline \multicolumn{6}{|l|}{ Lagomorpha } \\
\hline & Leporidae & Oryctolagus cuniculus & $21(32.3 \%)$ & $56.57(2.97 \%)$ & Introduced \\
\hline \multicolumn{6}{|l|}{ Erinaceomorpha } \\
\hline & Erinaceidae & Erinaceus europaeus europaeus & $7(10.8 \%)$ & $7.29(0.38 \%)$ & Introduced \\
\hline \multicolumn{6}{|c|}{ 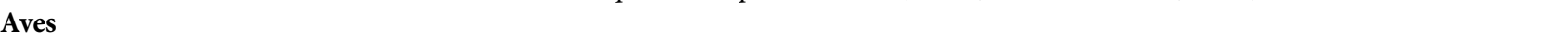 } \\
\hline \multicolumn{6}{|l|}{ Procellariiformes } \\
\hline & Procellariidae & Calonectris diomedea borealis & $1(1.5 \%)$ & $0.36(0.02 \%)$ & Native \\
\hline \multicolumn{6}{|l|}{ Falconiformes } \\
\hline \multicolumn{2}{|l|}{ Charadriiformes } & Buteo buteo rothschildi & $1(1.5 \%)$ & $0.18(0.01 \%)$ & Azores \\
\hline & Laridae & Larus michahellis atlantis & $1(1.5 \%)$ & $0.71(0.04 \%)$ & Azores \\
\hline & Scolopacidae & Scolopax rusticola & $5(7.7 \%)$ & $2.85(0.15 \%)$ & Native \\
\hline \multicolumn{6}{|l|}{ Columbiformes } \\
\hline & Columbidae & Columba livia domestica & $1(1.5 \%)$ & $0.18(0.01 \%)$ & Introduced \\
\hline & & Columba palumbus azorica & $7(10.8 \%)$ & $8.20(0.44 \%)$ & Azores \\
\hline \multicolumn{6}{|l|}{ Strigiformes } \\
\hline & Strigidae & Asio otus otus & $1(1.5 \%)$ & $1.25(0.07 \%)$ & Native \\
\hline \multicolumn{6}{|l|}{ Passeriformes } \\
\hline & Fringillidae & Carduelis chloris aurantiiventris & $2(3.1 \%)$ & $2.14(0.11 \%)$ & Introduced \\
\hline & & Fringilla coelebs moreletti & $15(23.1 \%)$ & $9.98(0.53 \%)$ & Azores \\
\hline & & Serinus canaria & $1(1.5 \%)$ & $0.36(0.02 \%)$ & Macaronesia \\
\hline & Motacillidae & Motacilla cinerea patriciae & $1(1.5 \%)$ & $1.25(0.07 \%)$ & Azores \\
\hline & Passeridae & Passer domesticus domesticus & $2(3.1 \%)$ & $0.36(0.02 \%)$ & Introduced \\
\hline & Sturnidae & Sturnus vulgaris granti & $1(1.5 \%)$ & $1.78(0.09 \%)$ & Azores \\
\hline & Sylvidae & Regulus regulus inermis & $1(1.5 \%)$ & $0.18(0.01 \%)$ & Azores \\
\hline & & Sylvia atricapilla gularis & $1(1.5 \%)$ & $0.71(0.04 \%)$ & Azores \\
\hline & Turdidae & Erithacus rubecula rubecula & $8(12.3 \%)$ & $4.28(0.23 \%)$ & Native \\
\hline & & Turdus merula azorensis & $29(46.1 \%)$ & $50.62(2.70 \%)$ & Azores \\
\hline \multirow{2}{*}{\multicolumn{6}{|c|}{$\begin{array}{l}\text { Reptilia } \\
\text { Squamata }\end{array}$}} \\
\hline & & & & & \\
\hline & Lacertidae & Teira dugesii & $2(3.1 \%)$ & $9.63(0.51 \%)$ & Introduced \\
\hline
\end{tabular}

${ }^{1}$ Range: Macaronesia, endemic to Macaronesia; Azores, endemic to Azores; Native, species range includes Azores; Introduced, species range does not include Azores.

The sampling effort needed to complete an inventory of terrestrial mammals usually exceeds 1,00o camera-trap days: Azlan (2006) needed 5,972 camera-trap days to record $61 \%$ of large mammals in Malaysian rainforests; Tobler et al. (2008) needed 1,440 and 2,340 camera-trap days to record 75 and $86 \%$ of medium and large mammals in the Amazonian moist forest, respectively; and Nakashima (2015) needed 4,165 camera-trap days to record $76 \%$ of medium and large mammals in the African lowland rainforest. In contrast, we needed only 465 camera-trap days to detect all introduced mammals on Terceira island. Because species richness generally increases with area, and oceanic islands are usually small and contain fewer species than mainland areas (Kier et al., 2009), the sampling effort to detect introduced species on oceanic islands is lower than on the mainland (Whittaker et al., 2017).

We recommend deploying camera traps for short periods in a given area and then moving them to enlarge the overall sampling area and to avoid spatial bias, especially if only few camera traps are available. We used five camera traps for 8-day periods, as in other studies (Rendall et al., 2014). We detected most of the introduced species 


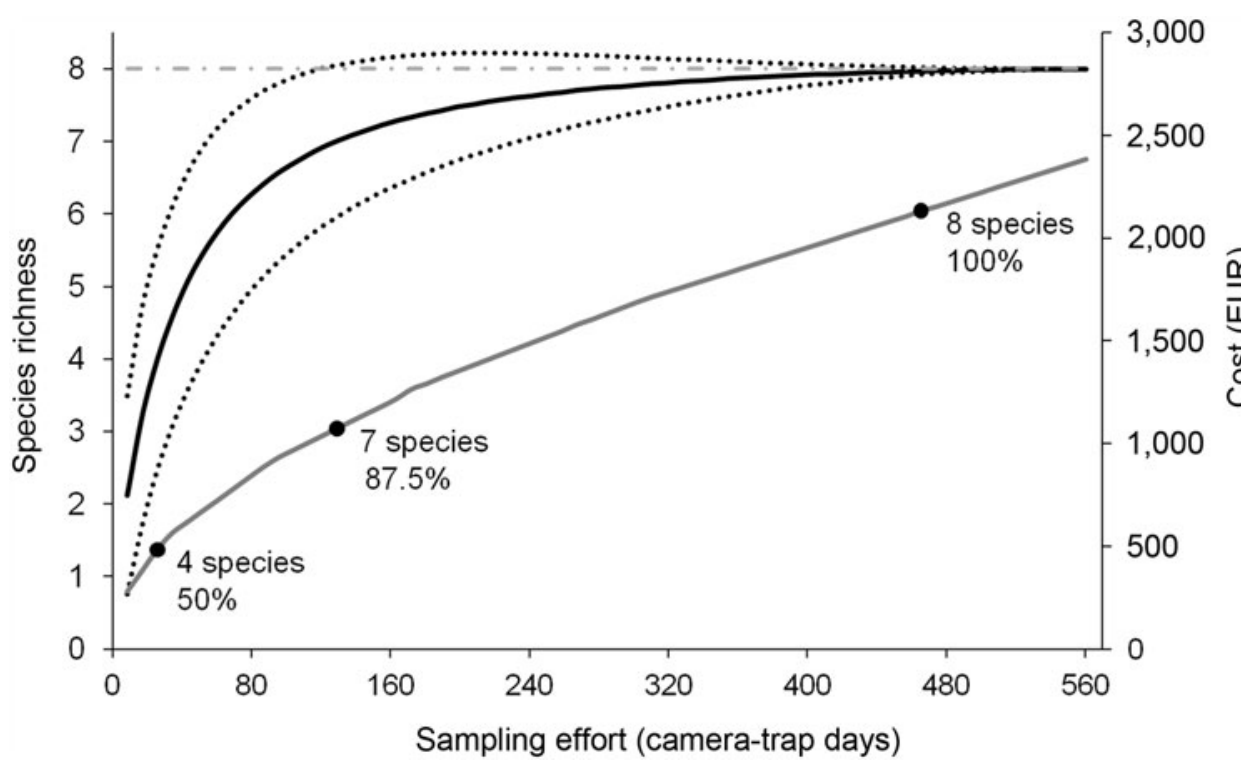

FIG. 2 Relationship between sampling effort, species richness and cost. The black solid line shows the species accumulation curve, which approaches an asymptote (grey dashed-dotted line) as sampling effort increases. The black dotted lines indicate the $95 \%$ CI. The grey solid line shows the economic costs of the camera-trapping survey. Black dots indicate the absolute number, and per cent of the total, of introduced mammal species detected during the survey.
TABLE 2 Information at site level of naïve occupancy estimation, estimated occupancy $(\psi)$, cumulated detection probability and number of sampling days required to determine a site-specific absence at $95 \% \mathrm{CI}$, assuming constant detection probability $\mathrm{P}($.$) .$

\begin{tabular}{|c|c|c|c|c|}
\hline Species & $\begin{array}{l}\text { Naïve } \\
\text { estimate }\end{array}$ & $\psi \pm \mathrm{SE}$ & $\begin{array}{l}\text { Detection } \\
\text { probability }\end{array}$ & $\begin{array}{l}\text { No. of } \\
\text { survey } \\
\text { days } \\
\text { required }\end{array}$ \\
\hline Rattus spp. & 0.85 & $0.85 \pm 0.04$ & 1.00 & 0.35 \\
\hline Mus musculus & 0.15 & $0.17 \pm 0.05$ & 0.94 & 1.04 \\
\hline $\begin{array}{l}\text { Oryctolagus } \\
\text { cuniculus }\end{array}$ & 0.32 & $0.35 \pm 0.06$ & 0.94 & 1.05 \\
\hline Erinaceus europaeus & 0.11 & $0.40 \pm 0.36$ & 0.29 & 8.80 \\
\hline Felis catus & 0.26 & $0.28 \pm 0.06$ & 0.94 & 1.08 \\
\hline Mustela nivalis & 0.08 & $0.08 \pm 0.10$ & 0.07 & 38.48 \\
\hline Mustela putorius & 0.02 & $0.02 \pm 0.02$ & 0.05 & 62.23 \\
\hline
\end{tabular}

(Table 2). However, the sampling effort was not sufficient to determine the absence of mustelids ( 38 and 62 required sampling days for the weasel and ferret, respectively). Overall, the best strategy to detect all introduced mammals on oceanic islands is to sample many locations for short periods (Si et al., 2014), although longer sampling periods are needed to monitor rare species at site level.

The detection probability of species may change because of seasonal effects. Generally it is higher in the breeding season when wildlife activity increases, although some species breed all year (e.g. rodents). The sampling period should thus coincide with high wildlife activity. We also recommend to rotate the camera traps between sites during the year to avoid seasonal bias.

Camera traps are generally used to survey medium-sized and large mammals (Srbek-Araujo \& Garcia, 2005; Tobler et al., 2008). Although there is a positive relationship between body weight and photographic capture rate (Tobler et al., 2008), we also used camera traps to detect small mammals, as have previous studies (MCCleery et al., 2014; Rendall et al., 2014; Taylor et al., 2014). Species detectability depends on whether cameras face outwards or downwards (Taylor et al., 2014). For example, downwardfacing cameras are more effective for detecting small mammals. However, we estimated the same detection probability of rodents as in a previous study (Rendall et al., 2014), although we could not distinguish between both Rattus species in all images from outward-facing cameras. Capture frequency is higher when camera traps face outwards because the detection area is wider (Taylor et al., 2014). We therefore recommend outward-facing camera traps for monitoring of multiple species across a range of body sizes.

Although camera trapping requires high initial costs, this is offset by the low fieldwork effort (Silveira et al., 2003). It cost EUR 2,133 to detect and monitor all introduced mammals on Terceira, which decreased by $35 \%$ the next year because equipment was reused. Camera trapping is the most cost-effective non-invasive method to monitor wildlife (Silveira et al., 2003; Lyra-Jorge et al., 2008; Monterroso et al., 2014), but we recommend complementary techniques (e.g. direct observation and sign surveys) to maximize detection probability, especially for rare species. Camera trapping is the best survey technique for a rapid assessment of introduced wildlife in varying environmental conditions (Silveira et al., 2003). To keep costs low, we recommend purchasing a small number of camera traps and maximizing the number of survey locations by moving the cameras. In conclusion, camera trapping is an efficient survey technique for detecting and monitoring introduced mammal species on oceanic islands. 
Acknowledgements We thank Jose Sarangollo, David Rodilla, María Olivo, Sophie Wallon and Luis Ansias for their assistance during fieldwork. LLL was supported by a grant from the Fundação para a Ciência e Tecnologia-FCT (SFRH/BD/115022/2016).

Author contributions Both authors contributed equally to all aspects of this research.

\section{Conflicts of interest None.}

Ethical standards This study abided by the Oryx guidelines on ethical standards.

\section{References}

Azlan, J.M. (2006) Mammal diversity and conservation in a secondary forest in Peninsular Malaysia. Biodiversity and Conservation, 15, 1013-1025.

Biber, E. (2002) Patterns of endemic extinctions among island bird species. Ecography, 25, 661-676.

Blackburn, T.M., Cassey, P., Duncan, R.P., Evans, K.L. \& Gaston, K.J. (2004) Avian extinction and mammalian introductions on oceanic islands. Science, 305, 1955-1958.

Blumstein, D.T. \& Daniel, J.C. (2005) The loss of anti-predator behaviour following isolation on islands. Proceedings of the Royal Society B: Biological Sciences, 272, 1663-1668.

Borges, P.A.V., Costa, A., Cunha, R., Gabriel, R., Gonçalves, V., Martins, A.F. et al. (2010) A List of the Terrestrial and Marine Biota from the Azores. Princípia, Cascais, Portugal.

Cabral, M.J., Almeida, J., Almeida, P.R., Delliger, T., Ferrand De Almeida, N., Oliveira, M.E. et al. (2005) Livro Vermelho dos Vertebrados de Portugal. Instituto da Conservação da Natureza, Lisbon, Portugal.

Colwell, R.K. (2013) EstimateS: Statistical Estimation of Species Richness and Shared Species from Samples. Version 9.1. User's guide and application at EstimateS. viceroy.colorado.edu/estimates [accessed 16 March 2020].

Courchamp, F., Chapuis, J.L. \& Pascal, M. (2003) Mammal invaders on islands: impact, control and control impact. Biological Reviews, 78, 347-83.

De Bondi, N., White, J.G., Stevens, M. \& Cooke, R. (2010) A comparison of the effectiveness of camera trapping and live trapping for sampling terrestrial small-mammal communities. Wildlife Research, 37, 456-465.

Doherty, T.S., Glen, A.S., Nimmo, D.G., Ritchie, E.G. \& DickMAN, C.R. (2016) Invasive predators and global biodiversity loss. Proceedings of the National Academy of Sciences, 113, 11261-11265.

Du Preez, B.D., Loveridge, A.J. \& Macdonald, D.W. (2014) To bait or not to bait: a comparison of camera-trapping methods for estimating leopard Panthera pardus density. Biological Conservation, 176, 153-161.

Frutuoso, G. (1561) Saudades da Terra. Instituto Cultural de Ponta Delgada, Ponta Delgada, Portugal.

Gonzalez-Esteban, J., Villate, I. \& Irizar, I. (2004) Assessing camera-traps for surveying the European mink, Mustela lutreola (Linnaeus, 1761), distribution. European Journal of Wildlife Research, 50, 30-36.

Gregory, T., Rueda, F.C., Deichmann, J., Kolowski, J. \& Alonso, A. (2014) Arboreal camera trapping: taking a proven method to new heights. Methods in Ecology and Evolution, 5, 443-451.

Hedwig, D., Kienast, I., Bonnet, M., Curran, B.K., Courage, A., Boesch, C. et al. (2018) A camera trap assessment of the forest mammal community within the transitional savannah-forest mosaic of the Batéké Plateau National Park, Gabon. African Journal of Ecology, 56, 777-790.

Hervías, S., Oppel, S., Medina, F.M., Pipa, T., Díez, A., Ramos, J.A. et al. (2014) Assessing the impact of introduced cats on island biodiversity by combining dietary and movement analysis. Journal of Zoology, 292, 39-47.

Hortal, J., Triantis, K.A., Meiri, S., Thébault, E. \& Sfenthourakis, S. (2009) Island species richness increases with habitat diversity. The American Naturalist, 174, 205-217.

Hines, J.E. (2006) PRESENCE 2.2-Software to Estimate Patch Occupancy and Related Parameters. mbr-pwrc.usgs.gov/software/ presence.html [accessed 16 March 2020].

Howald, G., Donlan, C.J., Galvan, J.P., Russell, J.C., Parkes, J., SAmANiEgo, A. et al. (2007) Invasive rodent eradication on islands. Conservation Biology, 21, 1258-1268.

Kier, G., Kreft, H., Ming, T., Jetz, W., Ibisch, P.L., Nowicki, C. et al. (2009) A global assessment of endemism and species richness across island and mainland regions. Proceedings of the National Academy of Sciences of the United States of America, 106, 9322-9327.

Lyra-Jorge, M.C., Ciocheti, G., Pivello, V.R. \& Meirelles, S.T. (2008) Comparing methods for sampling large- and medium-sized mammals: camera traps and track plots. European Journal of Wildlife Research, 54, 739-744.

Mathias, M.D.L., Ramalhinho, M.G., Santos-Reis, M., Petrucci-Fonseca, F., Libois, R., Fons, R. et al. (1998) Mammals from the Azores islands (Portugal): an updated overview. Mammalia, 62, 397-408.

MCCleery, R.A., Zweig, C.L., Desa, M.A., Hunt, R., Kitchens, W.M. \& PerCival, H.F. (2014) A novel method for camera trapping small mammals. Wildlife Society Bulletin, 38, 887-891.

McKinney, M.L. \& Lockwood, J.L. (1999) Biotic homogenization: a few winners replacing many losers in the next mass extinction. Trends in Ecology \& Evolution, 14, 450-453.

Millennium Ecosystem Assessment (2005) Ecosystems and Human Well-Being: Biodiversity Synthesis. World Resources Institute, Washington, DC, USA.

Monteiro, L.R., Ramos, J.A. \& Furness, R.W. (1996) Past and present status and conservation of the seabirds breeding in the Azores Archipelago. Biological Conservation, 78, 319-328.

Monterroso, P., Rich, L.N., Serronha, A., Ferreras, P. \& Alves, P.C. (2014) Efficiency of hair snares and camera traps to survey mesocarnivore populations. European Journal of Wildlife Research, 6o, 279-289.

NAKASHima, Y. (2015) Inventorying medium- and large-sized mammals in the African lowland rainforest using camera trapping. Tropics, 23, 151-164.

Nogales, M., Martin, A., Tershy, B.R., Donlan, C.J., Witch, D., Puerta, N. et al. (2004) A review of feral cat eradication on islands. Conservation Biology, 18, 310-319.

O’Connell, A.F., Nichols, J.D. \& Karanth, K.U. (2011) Camera Traps in Animal Ecology: Methods and Analyses. Springer, London, UK.

Olson, E.R., Marsh, R.A., Bovard, B.N., Randrianarimanana, H.L., Ravaloharimanitra, M., Ratsimbazafy, J.H. \& King, T. (2012) Arboreal camera trapping for the Critically Endangered greater bamboo lemur Prolemur simus. Oryx, 46, 593-597.

Pettorelli, N., Lobora, A.L., Msuha, M.J., Foley, C. \& Durant, S.M. (2010) Carnivore biodiversity in Tanzania: revealing the distribution patterns of secretive mammals using camera traps. Animal Conservation, 13, 131-139.

Rendall, A.R., Sutherland, D.R., Cooke, R. \& White, J. (2014) Camera trapping: a contemporary approach to monitoring invasive 
rodents in high conservation priority ecosystems. PLOS ONE, 9, e86592.

Rovero, F. \& Marshall, A.R. (2009) Camera trapping photographic rate as an index of density in forest ungulates. Journal of Applied Ecology, 46, 1011-1017.

SI, X., KAYS, R. \& Ding, P. (2014) How long is enough to detect terrestrial animals? Estimating the minimum trapping effort on camera traps. PeerJ, 2, e374.

Silveira, L., JА́сомо, A.T.A. \& Diniz-Filho, A.F. (2003) Camera trap, line transect census and track surveys: a comparative evaluation. Biological Conservation, 114, 351-353.

Soberón, J. \& Llorente, J. (1993) The use of species accumulation functions for the prediction of species richness. Conservation Biology, 7, 480-488.

Srbek-Araujo, A.C. \& Garcia, A.C. (2005) Is camera trapping an efficient method for surveying mammals in Neotropical forests? A case study in south-eastern Brazil. Journal of Tropical Ecology, 21, 121-125.

StatSoft (2011) Statistica Version 10. StatSoft, Tulsa, USA.

TAYLOR, B.D., Goldingay, R.L. \& Lindsay, J.M. (2014) Horizontal or vertical? Camera trap orientations and recording modes for detecting potoroos, bandicoots and pademelons. Australian Mammalogy, 36, 60-66.

Tobler, M.W., Carrillo-Percastegui, S.E., Leite-Pitman, R., Mares, R. \& Powell, G. (2008) An evaluation of camera traps for inventorying large- and medium-sized terrestrial rainforest mammals. Animal Conservation, 11, 169-178.

Vitousek, P.M. (1988) Diversity and biological invasions of oceanic islands. In Biodiversity (eds E.O. Wilson \& F.M. Peter), pp. 181-189. National Academy of Sciences, Washington, DC, USA.

Vitousek, P.M., Loope, L. \& Adsersen, H. (1995) Islands: Biological Diversity and Ecosystem Function. Springer Verlag, Berlin, Germany.

Vitousek, P.M., Mooney, H.A., Lubchenco, J. \& Melillo, J.M. (1997) Human domination of Earth's ecosystems. Science, 277, 494-499.

Wearn, O.R. \& Glover-Kapfer, P. (2019) Snap happy: camera traps are an effective sampling tool when compared with alternative methods. Royal Society Open Science, 6, 181748.

Whittaker, R.J., Fernández-Palacios, J.M., Matthews, T.J., BorregaArd, M.K. \& Triantis, K.A. (2017) Island biogeography: taking the long view of nature's laboratories. Science, 357, 8326 